\title{
The Stress Levels of Employees in an Organization with Liminal Status: The Case of Gendarmerie in Turkey
}

\author{
Murat Kocanli1 (i), Aytul Kasapoglu ${ }^{2 *}$ \\ ${ }^{1}$ Crime Studies Center, Gendarmerie and Coast Guard Academy, Ankara, Turkey \\ ${ }^{2}$ Department of Sociology, Baskent University, Ankara, Turkey \\ Email: akadem105@yahoo.com,^makasapoglu@baskent.edu.tr
}

How to cite this paper: Kocanli, M., \& Kasapoglu, A. (2021). The Stress Levels of Employees in an Organization with Liminal Status: The Case of Gendarmerie in Turkey. Open Journal of Social Sciences, 9, 87-105. https://doi.org/10.4236/jss.2021.94009

Received: March 3, 2021

Accepted: April 11, 2021

Published: April 14, 2021

Copyright $\odot 2021$ by author(s) and Scientific Research Publishing Inc. This work is licensed under the Creative Commons Attribution International License (CC BY 4.0).

http://creativecommons.org/licenses/by/4.0/

\begin{abstract}
This study focuses on the stress levels as an expression of the difficulties experienced by the personnel working in a janus-faced mixed organization with both military and civilian characteristics. In order to overcome the "institution" and "occupation" distinction which is essential in military sociology studies, the focus has been on "uncertainties" rather than "essentialism" from a relational sociological perspective. In this context, both uncertainties in social relations (ambage) and uncertainties in values (ambiquity) have been tried to be analyzed by making use of sociology literature. The originality of this study is that it was conducted with a law enforcement force with military status trying to cope with foreigners coming as a result of irregular migration in their own country, instead of military personnel who were previously employed in a foreign society outside their own country (Azari et al., 2010). Due to the Covid-19 Pandemic, an online survey study was carried out with 44 people, including officers and non-commissioned officers. With the advantage that one of the researchers is a senior officer and the other is a senior sociologist, the data were analyzed and interpreted with the SPSS/25 program. Analyzes using advanced statistical techniques revealed that there was no significant relationship between stress and tenure and status, in other words, perceived stress did not differ according to these independent variables. Factor analysis results revealed that while the staff working in an organization with liminal status were more affected by both "institutional" and" occupational" stress factors, they were in a more positive situation in terms of stress measured by scale items that could be considered personal. At the end of the research, some suggestions were made for the development of military sociology.
\end{abstract}

\section{Keywords}

Military Sociology, Gendarmerie, Stress, Liminality, Uncertainties, Turkey 


\section{Introduction}

Since the foundation of sociology, it can be said that sociologists have views that will contribute to the studies to be done directly or indirectly on the security forces. No doubt, M. Weber comes first with his social and economic organization theory. It is also possible to see works that refer to the views of thinkers such as E. Durkheim (division of labor and solidarity) and K. Marx (conflict and change). In fact, it is possible to determine some common points based on opinions that seem independent from each other. Classifying levels of analysis, for example, is a common tradition in sociology. Sociological studies in the military field were grouped first by Kummel (2006) then by Soeters (2018). The common feature of both is that they classify military sociological studies according to their "level of analysis". For example, Kummel (2006) mentions three levels as individual/micro-meso and macro in military analyzes.

Similarly, Soeters (2018) divides military studies into three according to their level of analysis, but makes slightly different explanations about them. While analyzing three levels of military problems, he also gives a list of sociologists used, although some are forgotten.

In fact, it can be said that the three analysis levels specified by Kummel (2006) have transformed or differentiated themselves at different times. Because these levels of analysis have never remained the same throughout history. They have changed slowly or fast according to the spirit of the time. Therefore, the phenomenon of change must be taken into account in military sociology studies. For example, in Turkey, starting from the period of reorganization for the Ottoman army at all three levels of modernization is very important. Likewise, the army has played a leading role in Turkish Modernization as an institution. M. Kemal Ataturk as a soldier, the founder of modern Turkey, is a historical individual (Martin, 2006).

Although seen as secondary in the military field, some other extremely important issues are leadership, recruitment and retention, education, deployment conditions, welfare-happiness and stress of soldiers and their families. The common feature of these studies is that they are limited to work outside of the military's hot contact with the enemy and in safer areas. Because although all the founding sociologists talk about war and violence, most of the work they do and suggest is outside the real field of action, with some exceptions (Carlton-Ford \& Ender, 2002, 2010, 2009; Laurance et al., 2017). In fact, most of the military sociology journals are named Political-Military Relations for this reason. Such journals include the University of Florida Press (UF Press), Scimago Journal of Country Research (SJR), and the Routledge Book series of Political and Military Sociology Series as a book.

In sociology, as well as functionalist (Durkheim) or conflict (Marx) approaches on military, the constructionist perspective, which argues that reality is a construction, has become increasingly widespread (Berger \& Luckman, 1984). One conclusion that can be inferred from this is that different cultures have different 
approaches to the military. For example, the operation styles of the Anglo-Saxon, African or Russian Chinese armies are different. On the other hand, it is an inevitable reality called "isomorphism" that organizations exceeding a certain size in terms of organizational sociology and management sciences cross each other (Lammers, 2018; Kummel, 2006).

According to the literature (Kummel, 2006), there are typologies of wars as well as of soldiers. Military and military profession definitions are also re-made. For example, there are traditional and non-traditional definitions of military service. On the other hand, some concepts are also defined in order to adapt to new situations in the military role set called "cosmopolitan behavioral orientations" (Kummel, 2006: p. 419). For example, one of the main discussions in military sociology is about the distinction between "institution" and "occupation" (Moskos, 1977; Janowitz, 1977; Segal, 1986).

The place and power of the armed forces in a society is constantly changing. Because the armed forces are an agency within a particular political system in a given society. This agency, using organized violence, as in Turkey, carries out the preparation against external enemies. The police and gendarmerie are responsible for ensuring security within the country.

Historically, there are those who have made phenomenological analysis of the changes that the military has undergone from past to today. For example, according to Carl von Clausewitz (1989), the armed forces are instruments that are financed for the security of a particular state in today's modern age. They are mostly used to provide security against other states.

Today, as Huntington states in his book "The Soldier and the State", the army under the control of civilians or as Janowitz discusses, a system view in which the weight of the soldier decreases in decision-making processes has come to the fore. In fact, it should not be wrong to say that these views point to an understanding of an army in the service of civilians (Feaver, 1996) based on Weber's Bureaucracy Theory.

Opposition to political-military structures has increased in Western countries since the 1970s (Haltiner, 2006). The situation is similar properties in Turkey last 20 years, military power or tutelage is attempted to be controlled by the civil power. In addition, unlike other organizations in the past, the issue of unlimited liability to the superiors in the military had to be overlooked, especially with the increase in the ratio of people from different professions in the army. The key question here is how these changes will affect the military's effectiveness and cohesiveness.

\section{Military Culture: Stress and Emotional Labor}

Instead of giving place to very different definitions of culture here, to define it in the sense that it is used more in military literature, "military culture is a set of meanings, ideas, and symbols that are shared by the members of collective." (Alvesson \& Billing, 1997). It is also stated that this culture has changed over time. On the other hand, there are those who define culture as collective pro- 
gramming that separates members of one group from another (Hoftsede, 1991).

Three perspectives on army culture can be mentioned (Martin, 1992; Winslow, 2000): These can be listed as a) Integration, b) Differentiation and c) Fragmentation Perspective. In fact, there are naturally sub-cultures within a culture. For example, the specific cultures of the land, sea or air force are subcultures, so it can be said that the army is a collection of heterogeneous micro-cultures (Hannerz, 1992: p. 77). According to the fragmentation perspective, this situation can lead to chaos, political change and even anarchy. According to the integrative perspective, culture appears as a binding and overarching phenomenon.

While examining the culture of military organizations, various features are taken into consideration. The most important of these is the communal character of life in uniform in the army. Here hierarchy, discipline and control are essential (Lang, 1972). From here, we come to the dual distinction of the military in military sociology as "institution" and "occupation (Moskos \& Wood, 1988).

Military service is now a profession, especially in volunteer armies, and tasks given for a fee are fulfilled. Business like attitudes are, of course, common in such organizations. Here too, bureaucratic uniformity and standardization are tried to be achieved. However, in the long term, the gap between these uniformed and business organizations gradually opens (Kirkman \& Shapiro, 1997). As a result of westernization and individualization, the national armies of other countries will also be composed of more educated people using advanced technology and the armies will therefore become comparable with each other (Adler \& Borys, 1996).

The issue of stress, which is a global problem in state or public organizations, is also important for the study presented here. Studies on stress date back to ancient times. For example, the first study on stress was conducted by the American psychologist Cannon in 1915. Later works also deal with general breakdown of the body as reactions to modern life. Especially in this public sphere, it is possible to mention the four most important sources of stress (Adler \& Borys, 1996): a) Dissatisfaction with the work environment b) Lack of career development and advancement opportunities, c) Weakness of social relations within the organization d) Role uncertainties and conflict e) Excessive workload and busy schedule.

As well as stress, another concept that has been emphasized in military work lately is emotions. Emotional labor and second shift concepts are also important for our study (Horschild, 2018). Here it is useful to know Coser's (1974) greedy institution evaluation about military. This means that the army expects more work, loyalty and energy from its employees. Coser has given priests and housewives as an example for greedy. Horschild's contribution is about the ability to manage the emotions of the soldiers who fulfill their duties by using controlled violence. Emotion management is expected from the army in charge of the action. Although he has a weapon in his hand, the soldier must manage his emo- 
tions so that he does not use it unless necessary. Ben-Ari (1989, 1998), who conducted the first study on this subject, was actually interested in how soldiers behave in civilian life. It is clear that in the subject of de-escalation of emotions, Symbolic Interactionist Goffman's (2018) conceptualization of backstage is used.

\section{The Case of Turkish Gendarmerie:}

A systematic migration from Syria to Turkey beginning in 2011, which depends on the Ministry of Internal Affairs has led to an increase in the duties of the Gendarmerie General Command. In this context, the changes in the duties and powers of the gendarmerie, which started only in 2016 should be put forward. James Burk (2006) calls this "adaptive military”. The military organization adapts to the changes in its environment, especially with its technical infrastructure and experience. It is the duty of the military to develop the capacity to adapt to national and international changes in a situation of uncertainty and liminality. For this purpose, it is necessary to look at what the unchanging aspects are, showing continuity as much as the changes.

In this context, the Republic of Turkey was founded in 1923, gendarmerie is one of the most important institutions established in the period of the Ottoman Empire. The Ottoman Empire officially declared the modernization movements that it started in all its institutions, especially the civilian and military bureaucracy, with the Edict of Gulhane declared in 1839 in order to combat the West. Later, in 1869 , the legal basis of the gendarmerie was established by publishing the Asakir-i Zaptiye Regulation.

In the first years of the Republic period (1930), the definition of the Gendarmerie was made as "a law enforcement unit with military status". However, in this definition, it is also stated that the gendarmerie is the "military police force" responsible for the general security and public order, although it is affiliated with the Ministry of Internal Affairs. In addition, it was stipulated that the Gendarmerie was subordinate to the governors, who were the greatest civilian civil superior in each province. Although there were some different applications in the following years, with the arrangement made in 2016, the Gendarmerie General Command was re-attached to the Ministry of Internal Affairs, and the arrangement in the first years of the Republic was reverted. On the other hand, the Gendarmerie General Command is still working in close cooperation with the civilian police such as the Turkish National Police and military forces such as the Coast Guard Command.

Gendarmerie General Command is directly dependent on the Minister of Internal Affairs, a civilian political identity. This clearly shows that both the gendarmerie as an individual and the command as an organization have a "liminal" identity (Gennep, 1960; Turner, 1969), which sociologically means both civilian and military.

The gendarmerie has judicial, civil and military duties. It is possible to examine the content of these according to the information announced on the Gendarmerie's own websites and updated continuously (Official Site of Turkish Gendarmerie General Command, 2021, http://www.jandarma.gov.tr). 
a) Civil Duties:

To ensure safety and public order of $93 \%$ of Turkey's surface area, preventing, tracking and investigating all of trafficking kinds, taking and implementing the necessary measures to prevent all of crimes, to make the external protection of penal institutions and detention centers, take the necessary measures for the safe use of the rights and freedoms regulated in the Constitution and laws, collect intelligence, cooperate and share information with other intelligence and law enforcement agencies in order to ensure security and public order, identify crimes, identify and catch perpetrators of committed crimes and carry out traffic services and carry out operations related to traffic accidents that occur.

b) Judicial Duties:

Criminal Procedure in relation to crimes committed carrying out the procedures specified in the legislation and performing the judicial services related to them, to fulfill of Public prosecutor's orders on judicial duties

c) Military duties:

To perform military services rendered by law and presidential decrees.

\subsection{Research Problem}

It is an expected increase in the stress of the employees whose responsibilities are increasing in a mixed organization with a liminal identity. With the increase of the urban population over time, it seems that the duties of the gendarmerie in rural areas have been replaced by human and drug trafficking operations as well as intercity transportation, traffic or emergency rescue in disasters. Especially in the last 10 years, particularly the number of Syrians to Turkey has exceeded four million immigrants from the Middle East. Our borders have become a gateway for immigrants, especially immigrants who want to immigrate to European countries have started to risk their lives in the hands of human smugglers. It is possible to hear daily news in the newspapers that illegal immigrants were caught by the gendarmerie.

As it is known, one of the main discussions in military sociology is about the concepts of institution and occupation (Moskos, 1977; Janowitz, 1977; Segal, 1986). The research problem presented in this article as part of a larger study actually stems from the distinction between institution and occupation. In other words, the authorities and responsibilities of the personnel wearing military uniforms in their jobs, which are historically very important and require loyalty, in the units of the Gendarmerie Command in return for a certain salary, have been rather uncertain until recent years. Despite over four million Syrian immigrants in the last 10 years, although these uncertainties were tried to be removed to some extent with a new regulation in 2018 , the main problem of the research is the organizational stress experienced due to the lack of material, organization and legislation as well as this ambiguous identity.

Recognizing that stressful attitudes are important, researching them is as effective as being factual, scientific, and analytical. Therefore, in the military soci- 
ology study, which is the basis of this article, the stress levels of the soldiers working in the gendarmerie command were tried to be measured.

\subsection{Objectives}

In this article, the following questions were tried to be answered by interviewing the personnel working in the gendarmerie units related to migration:

a) What is the average stress level of the staff?

b) What are the factors or predictors (institutional, occupational or personal) that lead to staff stress?

c) What can be said about the relationship between the gendarmerie being a rooted institution that requires loyalty and being an occupation paid for the maintenance of life? In other words, what can be said about institutional loyalty, that is, the unity of moral values and occupational expectations, that is, liminality?

\subsection{Importance}

Previous military sociology studies were mostly related to the stress experienced by the soldiers who were assigned in a foreign country while trying to cope with the problems arising from the differences in language, culture and geography (Azari et al., 2010). The importance of this study stems from the fact that it focuses on the gendarmerie who has been struggling with irregular immigration mostly from Syria in the last 10 years. In other words, the gendarmerie, which is the subject of investigation, tries to deal with both immigrant foreigners in their own country and Turkish citizens who react to them.

\subsection{Limitations}

This research was limited to the provinces, which are the responsibility of the gendarmerie, and the years 2009-2019 in terms of time. Because irregular migration to Turkey from Syria, which began in 2009. On the other hand, the study is limited to 15 provinces where irregular migration occurs most.

\subsection{Method}

This study is basically a quantitative study conducted according to the positivist epistemology. In the research, a questionnaire consisting of 28 closed-ended questions was applied.

In this study, the perceived stress scale, which was developed by Baltas and Baltas (2008), inspired by Cohen and William (1988), was used. In this Likerttype scale, there are 15 items that list the situations encountered in work life. In the scale, answers are graded from 1 to 5 . In this study, the Cronbach alpha value of the scale was found to be extremely high (0.84). Collected data were analyzed with SPSS/25 program.

Universe and Sample: The universe of this study is the personnel working in the gendarmerie commands in the provinces receiving the most immigration. For the purposes of the study, a total of 15 provinces were identified as Antalya, 
Aydın, Çanakkale, Edirne, Hakkari, Hatay, Mersin, İstanbul, İzmir, Kırklareli, Kahramanmaraş, Mardin, Muğla, Van and Şırnak, which are thought to reflect the characteristics of the universe and where the most irregular migration cases occur. Because 69,329 of 89,927 cases in total occurred in these provinces and they constitute majority of the total cases.

The questionnaire forms were applied to a total of 44 personnel, three from each province (one officer and two NCO'S), working in the Anti-Migration and Human Trafficking units of the Provincial Gendarmerie Command in 15 provinces. Officers working in these provinces work as branch managers and make up the whole universe. Therefore, no sampling was used for the officers, and all of them were taken as full counts. Non-commissioned officers were selected from those with more professional experience working in the field.

Before starting this study, ethical committee approval was obtained from the Gendarmerie Command. It is important for the reliability of the study to ensure that it is not known to whom the answers belong. A web-based questionnaire arrangement has been made to ensure anonymity in the answers. Thus, a high participation rate of $98 \%$ was achieved in the research.

\section{Findings and Discussion}

In this section, first of all, information about the demographic characteristics of the sample is given. The mean age of the sample is 38.34 and its standard deviation is 5.89. This situation is expected due to the fact that junior officers as well as senior officers are included in the sample. The majority of the personnel $(81.8 \%)$ in terms of educational status are college or university graduates. In the gendarmerie management system, officers are considered as middle-top managers, and the sample of the study included 14 officers. When the ratio of the noncommissioned officers working in the field is examined, it can be said that $25 \%$ of them are in the rank of senior sergeant, so they are quite experienced. When the tenure of the sample in the profession is examined, it is understood that $70.5 \%$ of them have experience between $10-24$ years. As a matter of fact, the experience year average of the sample is 16.84 and the standard deviation is 7.70. The fact that the standard deviation is very high is an indication that the group is very heterogeneous. As a matter of fact, the majority of the sample is quite inexperienced because $56.8 \%$ of them have $0-2$ years of experience. Almost half of the sample (47.7\%) works in the CMHST/ GKIT, which is the unit responsible for combating irregular migration in the field. When the distribution of the sample according to the task they are working on is examined, it is seen that $52.3 \%$ are "department supervisors".

In the study, firstly, the average score and standard deviation of the staff from the stress scale were analyzed. While the mean of the stress scale is 35.06 , its standard deviation is 11.06 .

The distribution of the responses given to 15 items (from one/never to five/very often points) in the scale is summarized in Table 1. 
The mean, mode, median, standard deviation and standard error of the responses to each item are given in Table 2.

Table 1. Distribution of Responses \% $(\mathrm{N}=44)$.

\begin{tabular}{lcccccc}
\hline \multicolumn{1}{c}{ Items } & Never & $\begin{array}{c}\text { Almost } \\
\text { never }\end{array}$ & Sometimes & $\begin{array}{c}\text { Fairly } \\
\text { often }\end{array}$ & Very often & Total \\
\hline 1. Authorization & 18.2 & 31.8 & 27.3 & 18.2 & 4.5 & 100 \\
2. Hesitation & 41.7 & 20.5 & 20.5 & 6.8 & 4.5 & 100 \\
3. Promotion & 31.8 & 13.6 & 31.8 & 13.6 & 9.1 & 100 \\
4. Workload & 25.0 & 20.5 & 29.5 & 15.9 & 9.1 & 100 \\
5. Demands & 31.8 & 22.7 & 25.0 & 13.6 & 6.8 & 100 \\
6. Education & 40.9 & 31.8 & 13.6 & 4.5. & 9.1 & 100 \\
7. Evaluation & 15.9 & 13.6 & 13.6 & 31.8 & 25.0 & 100 \\
8. Information & 40.9 & 18.2 & 29.5 & 9.1 & 2.3 & 100 \\
9. Worry & 52.3 & 20.5 & 15.9 & 11.4 & - & 100 \\
10. Acceptance & 63.6 & 20.5 & 6.8 & 6.8 & 2.3 & 100 \\
11. Direction & 50.0 & 20.5 & 13.6 & 13.6 & 2.3 & 100 \\
12. Expectations & 52.3 & 29.5 & 4.5 & 6.8 & 6.8 & 100 \\
13. Quality & 27.3 & 15.9 & 29.5 & 20.5 & 6.8 & 100 \\
14. Forced & 47.7 & 20.5 & 11.4 & 9.1 & 11.4 & 100 \\
15. Family & 22.7 & 6.8 & 18.2 & 36.4 & 15.9 & 100 \\
\hline
\end{tabular}

Table 2. Central tendency results of scale items $(\mathrm{N}=44)$.

\begin{tabular}{lccccc}
\hline \multicolumn{1}{c}{ Scale items } & Mean & Mode & Median & $\begin{array}{c}\text { Standard } \\
\text { deviation }\end{array}$ & $\begin{array}{c}\text { Standard } \\
\text { error }\end{array}$ \\
\hline 1. Authorization & 2.59 & 2.00 & 2.50 & 1.13 & 0.17 \\
2. Hesitation & 2.00 & 1.00 & 2.00 & 1.18 & 0.18 \\
3. Promotion & 2.55 & 1.00 & 3.00 & 1.31 & 0.20 \\
4. Workload & 2.64 & 3.00 & 3.00 & 1.28 & 0.19 \\
5. Demands & 2.40 & 1.00 & 2.00 & 1.26 & 0.19 \\
6. Education & 2.09 & 1.00 & 2.00 & 1.25 & 0.19 \\
7. Evaluation & 3.36 & 4.00 & 4.00 & 1.42 & 0.21 \\
8. Information & 2.14 & 1.00 & 2.00 & 1.13 & 0.17 \\
9. Worry & 1.86 & 1.00 & 1.00 & 1.07 & 0.16 \\
10. Acceptance & 1.64 & 1.00 & 1.00 & 1.04 & 0.16 \\
11. Direction & 1.98 & 1.00 & 1.50 & 1.19 & 0.18 \\
12. Expectations & 1.86 & 1.00 & 1.00 & 1.21 & 0.18 \\
13. Quality & 2.64 & 3.00 & 3.00 & 1.28 & 0.19 \\
14. Forced & 2.16 & 1.00 & 1.00 & 1.41 & 0.21 \\
15. Family & 3.16 & 4.00 & 4.00 & 1.41 & 0.21 \\
\hline
\end{tabular}


Table 3. Zero-order (Pearson Correlation)

\begin{tabular}{ccccc}
\hline Variables & Total scale score & Statue & Tenure & Age \\
\hline Tot. scale score & - & & & \\
Statue & -0.034 & - & & \\
Tenure & -0.015 & 0.091 & - & \\
Age & -0.124 & 0.161 & $0.827^{\star *}$ & - \\
\hline
\end{tabular}

${ }^{*} 0.01$ correlations is significant at the 0.01 level (2-tailed).

On the other hand, it was investigated whether there is a statistically significant relationship between scale scores and independent variables such as the staff's tenure and the rank as officer or noncommissioned. However, results of both zero-order and regression analysis showed that there was no significant statistical relationship between the stress scale and tenure and ranks. Just as expected, a significant relationship was found between age and tenure. As age increases, experience or tenure naturally increases (Table 3).

In addition, regression analysis was performed as a single item of scale with independent variables such as rank, education level and tenure. Analyzes showed that there was a statistically significant relationship between only status and authorization (having authority $p<0.047$ ) and education required by the profession and education level $(p<0.045)$. The findings are in the expected direction, as it is common for officers to have more authority than other personnel, as well as post-graduate training personnel to have more professional knowledge than others.

Upon this, when factor analysis was applied, it was understood that the 15-item scale was divided into three subgroups as "institutional", "occupational" and "personal" (See Table 4).

At this stage of the analysis, the scale items indicated by the factor analysis were transformed into three groups as institutional, occupational and personal, and discussed in detail in the findings and discussion section.

\subsection{Institutional Factors}

In this group, there are six scale items such as authorization, evaluation, information, acceptance, direction and force to act differently. The total mean score of the answers in this group is 13.36 and the standard deviation is 3.92. Below, the responses to the six scale items in this group are discussed proportionally (\%) using individual observations and literature.

Authorization ("Do you feel that you are not authorized enough to fulfill your responsibilities?"

When the answers given by the participants to this question are examined, the answers to feel that they have authority are in the majority. However, only $22.7 \%$ of the sample replied that they did not feel competent. In other words, it is understood that the vast majority of the sample consisting of personnel struggling with irregular immigration think they have the necessary authority in terms of 
Table 4. Results of factor analysis.

\begin{tabular}{cccc}
\hline Scale items & Institutional & Occupational & Personal \\
\hline Authorization & 0.849 & & \\
Evaluation & 0.812 & & \\
Acceptance & 0.743 & & \\
Direction & 0.706 & & \\
Forced & 0.631 & 0.796 & \\
Quality & & 0.745 & \\
Workload & & 0.643 & \\
Demands & & 0.624 & 0.912 \\
Hesitation & & 0.600 & 0.592 \\
Family & & & 0.527 \\
Education & & & 0.519 \\
Promotion & & & \\
Expectations & & & \\
Worry & & & \\
\hline
\end{tabular}

Rotation Method: varimax with Kaiser Normalization; Kaiser-Meyer-Olkin Measuere of Sampling Adequecy: 0.820; Bartlett's Test of Sphericty: Chi-Squre: 439.947, $p<0.000$.

responsibility-authority relationship in the field. On the other hand, when staff are first assigned to a region they have not lived in before, there is a possibility that they may think that they do not have the necessary authority to fulfill their law enforcement duties. It should also be taken into account that it needs time to adapt to the region.

Evaluation ("Do you know how your supervisors evaluate your business success?)

When the answers given to this question were analyzed, it was found that more than half of the personnel interviewed (56.8\%) generally knew the evaluations of their supervisors about them. These data can be interpreted as the supervisors also share their evaluations about their personnel and motivate their personnel positively. As a matter of fact, in some studies, it has been revealed that the presence of supervisors supporting the employees in the organization ensures that the general perception of institutional support of the employees is high. It has been demonstrated that an oppressive or restrictive supervisor perception negatively affects the productivity of employees (Scott \& Bruce, 1994). Since the perceptions of organizational trust and commitment are high in organizations where employees perceive the supervisor's support highly (Suliman, 2001: p. 55), it can be said that as an organization, it is tried to establish good communication with the personnel in the gendarmerie.

Obtaining information ("Do you encounter difficulties in obtaining the information necessary to do your job?")

When the distribution of the answers is examined, it can be said that the rate 
of those who stated that they have never and rarely encountered obstacles is quite high (59.1\%). Considering the from time to time responses, the rate of accessing information is much higher $(88.69 \%)$. This data shows that the majority of the sample did not encounter any obstacle in accessing information in order to effectively combat irregular migration while working in the field. These data are important as one of the factors leading to a low average stress level of staff.

Acceptance from the environment ("Here do you feel that you are not liked and accepted by those around you?"

The majority of the participants (63.6\%) answered this question meaning that they are accepted by their colleagues around and their work is respected. As Azari et al. (2010) stated, emotional and personal characteristics of the person are among the factors that increase stress. The negative characteristics of the personnel working in the Gendarmerie branches such as being angry, acting aggressively and acting with their own will may cause them to be questioned about their duty by keeping them away from unity and solidarity. For this reason, it is extremely important that staff think they are accepted and respected. Because poor social relationships in organizations are a source of stress (Adler \& Borys, 1996).

To direct the supervisor ("Do you feel like you cannot direct your supervisor's decisions and behaviors that affect you?")

When the answers given to this question are examined, the majority of the sample (50\% never; $20.5 \%$ rarely; a total of $70.5 \%)$ stated that they can direct their superiors in decisions that affect them. This finding is an indication that the supervisor-staff communication is positive. It is also a sign of a situation that will have a positive impact on the tasks in the field. In other words, the establishment of an effective management system between the supervisor and the personnel in the units where the personnel work, and the healthy communication can be considered as a factor that reduces occupational stress. It is also possible to establish an indirect interest in the management of emotions (Horschild, 2018; Ben-Ari, 1989).

Forced to act differently ("Do you have to do your job out of it, even though you know how to do better?")

According to the answers given to this question, the majority of the sample (68.2\%) stated that they were never or rarely forced to act differently. On the other hand, one third (32\%) of the gendarmerie personnel stated that although they knew the procedures for performing their duties effectively, they could not do so due to the inadequacy of the organization, materials and staff structure, as well as the legal legislation not allowing it. All of these, uncertainties in business relationships and ambiguous situations in future predictions may cause difficulties for staff to fully focus on the task.

\subsection{Occupational Factors}

In this group, there are five items such as quality, workload, demands, hesitation 
and family. While the mean scale score of this group is 12.86 , its standard deviation is 4.96 .

Work quality ("Do you think that the amount of work you have to do affects the quality of your job negatively?")

In the answers given to this question, those who sometimes, often and almost always think as negative effects are quite high (56.8\%). It would not be wrong to say that irregular migration, which has gradually increased since 2011 affects the quality of the work done due to the insufficiency of the existing organization, material and staff structure as well as the fact that the legal legislation is not deterrent and effective.

Heavy workload (Do you feel like you have too heavy a workload to finish on a normal working day?")

When the answers given are examined, a significant part (55\%) of varying degrees stated that they have a heavy workload that cannot be completed on a normal working day. It would not be wrong to say that the number of staff available is not enough to effectively combat irregular migration cases. It is clear that the units need much more staff to assist both the local population and the immigrants in their daily administrative, judicial and military problems. In other words, it can be said that dealing with a workload over their capacity is a factor that increases their perceived stress level. As a matter of fact, there are findings in this direction in the literature (Adler \& Borys, 1996).

Demands ("Do you think you cannot meet the conflicting demands of the people around you?" It is necessary to evaluate the answers given to this question in two stages as colleagues and the service environment. More than half of the sample (54.5\%) stated that they never and rarely faced conflicting demands. In addition, one in four (25\%) responded as sometimes. In the light of all these data, it can be said that the vast majority of the sample $(79.5 \%)$ think positively about meeting the conflicting demands of the people around them.

Hesitation ("Do you hesitate about the purpose of your job and the responsibilities you bear?")

According to the answers given to this question, a very high rate of participants, almost half (47.7\%), stated that they never hesitated. This data can also be interpreted as that the personnel working in the field do not experience serious difficulties in terms of their responsibilities to combat irregular migration. On the other hand, $52.3 \%$ stated that they had trouble at any time. In this sense, the uncertainties and difficulties encountered during the duty for the personnel working for the first time in the region where irregular migration is intense can be evaluated as factors that increase the stress on the personnel themselves. This situation can be defined as "ambage", which means uncertainty in the form of not fully fulfilling the role expected from him, which has an important place in White et al. (2013) classification. It is possible that, while struggling with irregular migration, sometimes hesitations in terms of duties and responsibilities are related to uncertainty in social relations. 
Affecting family life ("Do you feel that your job is an obstacle to your family life?")

It is observed that more than half of the staff (52.3\%) think that their work affects family life negatively in general. When the answers given to the from time-to-time option are added to this distribution, the rate rises to $70.5 \%$. The most important result that emerges from this is that the majority think that their profession negatively affects family life and that they cannot take care of family members adequately. Azari et al. (2010) emphasizes that being a spouse and family of law enforcement personnel is a cause of stress in itself. Generally, law enforcement personnel do not bring their family with them for various reasons, especially security and education of children when they work in foreign cultures. This situation of living alone and opening a second home is a factor that increases the stress of the staff themselves.

\subsection{Personal Factors}

Education ("Do you think you don't have the training required for your job?")

A very large part of the participants stated that they have the necessary training (85\%). In other words, it can be said that the Gendarmerie General Command provided the necessary training for the personnel struggling with irregular migration. In addition, they are provided with a 15-day orientation training on the economic, social, cultural and security structures of the province they are assigned to. According to the literature, education is very important (Weick, 1993), for example, education is also required to learn to be cold-blooded by wearing a mask (Weibull, 2012). It can be said that Goffman (2018) and his back-stage metaphor also make sense here.

Promotion ("Do you doubt the opportunities available to you in terms of development and promotion in your business?")

When the answers given are analyzed, it is understood that the majority of them (77.3\%) think positively about providing them with advancement and development opportunities within the framework of combating irregular migration. It can be said that there is no need to worry about the hardworking personnel who do their duties well, since the principles of merit are followed very seriously in the Gendarmerie. The data are therefore in the expected direction. However, it is known that the lack of progress opportunities increases stress (Adler \& Borys, 1996).

Knowing the expectations ("Would you be hesitant about what exactly those you work with expect from you?"

When the answers given to this question were examined, the majority of the sample (52.3\% never, $29.52 \%$ rarely) stated that they were hesitant. This distribution shows that a high percentage $(81.8 \%)$ of the staff are self-confident and aware of their duties. One of the main reasons for this is that the duties and responsibilities of each personnel working in the units are determined by legal leg- 
islation. They are dealing with irregular migration cases in the field in line with their job descriptions. On the other hand, it would not be wrong to say that environments that do not prevent, but enrich physical and psychological conditions reduce stress (Lamontagne et al., 2007).

Worry from decisions ("Are you worried about the decisions that will affect the lives of people you know?")

In this question, the never worried option is more than half (52.3\%). When rare and sometimes options are included, this rate is much higher (88.6\%). These findings show that the staff makes the decisions required by the task without hesitation. In some studies (Azari et al., 2010), it has been shown that high professional experience and tenure in the region of duty reduces the cultural and professional stress. In this context, it would not be wrong to say that the employment of experienced personnel in regions where irregular migration cases are intense plays an important role in reducing the stress level. The concept of "management of emotions" becomes important here as well (Horschild, 2018; Ben-Ari, 1989).

\section{Conclusion}

As a result of the research, it can be said that the factors that cause the most stress at a close ratio are "institutional" and "occupational" in order of priority. Interestingly, however, factor analysis revealed that there is a third group. This factor, which is called a "personal" category by the researchers, seems to have a very low impact on perceived stress. It would not be wrong to say that staff members do not experience much stress from education, promotion, expectations and worry.

In fact, the staff are foreign to the culture of both the indigenous people and the immigrant population in the region where they work, especially the language, food, clothing and traditions. In this sense, both the uncertainty about the task and cultural differences can be considered as factors that increase the stress of the personnel for the personnel working for the first time in the region where irregular migration is intense. As a matter of fact, this situation is referred to as "ambiguity" in cultural values in the literature (White et al., 2013).

Because the duty of the gendarmerie as law enforcement is to prevent irregular immigration within the scope of administrative duties. On the other hand, when irregular migrants are caught, the gendarmerie struggles to provide them with shelter, food and the best health conditions. This situation can be sociologically defined as uncertainty in values (White et al., 2013). The way to eliminate or reduce possible conflict is to recognize and learn the values of the region and the foreign population as immigrants. As the uncertainties begin to disappear, it is likely that the cultural stress and thus the occupational stress will begin to decrease.

However, since the irregular immigrants display a multicultural structure, the languages spoken also differ. Considering the nationalities of the immigrants 
captured, it is seen that the population with different languages from countries such as Syria, Afghanistan, Pakistan, Iraq and Palestine is concentrated. Languages such as Arabic, Persian and Pashto stand out. Interpreters are used to provide the necessary communication with irregular migrants.

However, staff are expected to have the most up-to-date information at all times. Otherwise, feelings of distrust and uncertainty about the staff will develop in the supervisors and the professional stress of the employee will increase in return. It is naturally undesirable when high stress can lead to undesirable consequences such as aggression and inadequate attention to irregular migrants. It can be said that the most important factors that increase the stress of law enforcement personnel are the inadequacy of the instruction-material staff as well as the increased migration in the last 10 years. Although the high workload on the staff negatively affects the performance, the positive perception of the institutional identity has an important place in the success motivation, productivity and efficiency of the employees.

Although the institutional belonging of the gendarmerie personnel with a mixed structure as semi-military and half-civilians is high, they are found to be stressful in some issues both institutionally and occupationally, which is the most important indicator of the gendarmerie being a profession at the same time. Therefore, it is understandable that despite all the organization, material and staff inadequacies, the personnel obtained moderate scores on the stress scale.

In military organizations, the trend towards occupationalism rather than institutionalism is growing. In fact, it is necessary to know that most armies are Janus-faced organizations in a liminal way, both hot and cold. This concept is defined as the Janusian character organizations, as this concept comes from the Roman god Janus. But the reality is that with the arrival of more educated people and women, armies began to have more humanist structures instead of warriors and violence. Because there are citizens, customers and consumers who also use the services of armies. It requires the transformation of the armies, whose needs are met with the taxes paid by citizens, towards a form that respects politicians and the public as stakeholders. In short, today's armies have to balance the traditional basic principles of their culture with the changing conditions with reason and patience (Soeters \& Winslow, 2006).

Finally, it is possible to mention some suggestions for the development of Military in sociology as outlined below:

1) Research based on comparisons;

2) Researcher's own subjective thoughts and perceptions;

3) Academicians doing military sociology together with soldiers;

4) Working together quantitatively and qualitatively with mixed designs. Using visual materials, photographs and videos;

5) Not being enough with only narrow and small pictures, trying to understand the events by placing them in a wider frame. Here, Weberian Substantive 
rationality is valued rather than Durkheim's functional rationality;

6) Not only important events and persons, but also lower-level employees or people in the occupied country should be included in the study without marginalization. Analysis should be made without any method limitation. It also means learning to look differently, considering all the alternatives. This actually reminds us of Weber. This means understanding reality without neglecting all possibilities and then trying to explain events;

7) Instead of looking essentialist and dichotomous, process-based analyses should be done in a relational sociological and holistic way.

\section{Conflicts of Interest}

The authors declare no conflicts of interest regarding the publication of this paper.

\section{References}

Adler, P. S., \& Borys, B. (1996). Two Types of Bureaucracy: Enabling and Coercive. Administrative Science Quarterly, 41, 61-89. https://doi.org/10.2307/2393986

Alvesson, M., \& Billing, D. B. (1997). Understanding Gender and Organizations. London: Sage.

Azari, J., Dandeker, C., \& Neil, G. (2010). Cultural Stress: How Interactions with and among Foreign Populations Affect Military Personnel. Armed Forces \& Society, 36, 585-603. https://doi.org/10.1177/0095327X09358648

Baltas, Z., \& Baltas, A. (2008). Stres ve başa çıkma yolları. İstanbul: Remzi Kitabevi.

Ben-Ari, E. (1989). Masks and Soldiering: The Israeli Army and Palestinian Uprising. Current Anthropology, 4, 372-389. https://doi.org/10.1525/can.1989.4.4.02a00030

Ben-Ari, E. (1998). Mastering Soldiers, Conflict, Emotions and the Enemy in an Israeli Military Unit. Oxford: Berghan.

Berger, P., \& Luckman, T. (1984). Social Construction of Reality: A Treatise in the Sociology of Knowledge. Harmondsworth: Penguin.

Burk, J. (2006). Military Mobilization in Western Societies. In G. Caforio (Ed.), Handbook of the Sociology of Military (pp. 111-130). New York, NY: Springer. https://doi.org/10.1007/0-387-34576-0 7

Carlton-Ford, S., \& Ender, M. G. (2010). Handbook of War and Society: Iraq and Afghanistan. London: Routledge. https://doi.org/10.4324/9780203844335

Cohen, S., \& William, G. (1988). Perceived Stress in a Probability Sample of the US. In S. Spacapam, \& S. Oscamp (Eds.), The Social Psychology of Health. Claremont Symposium on Applied Social Psychology. Newbury Park, CA: Sage.

Coser, L. (1974). Greedy Institutions: Patterns of Undivided Commitment. New York, NY: Free Press.

Ender, M. G. (2002). Military Brats and Other Global Nomads: Growing-Up in Organization Families. Westport, CT: Praeger.

Ender, M. G. (2009). American Soldiers in Iraq: Mc Soldiers or Innovative Professionals? London: Routledge.

Feaver, P. (1996). The Civil-Military Problematique: Huntington, Janowitz, and the Question of Civilian Control. Armed Forces and Society, 23, 149-178.

https://doi.org/10.1177/0095327X9602300203 
Gennep, A. (1960). The Rites of Passage. M. B. Vizedom, \& G. L. Caffee (Trans.) London: Routledge and Kegan Paul.

Goffman, E. (2018). Total Institutions, Interaction Rituals, Street Level Bureaucrats. In J. Soeters (Ed.), Sociology and Military Studies: Classical and Current Foundations (pp. 91-102). London: Routledge.

Haltiner, K. W. (2006). The Decline of the European Mass Armies. In G. Caforio (Ed.), Handbook of the Sociology of Military (pp. 361-385). New York, NY: Springer. https://doi.org/10.1007/0-387-34576-0 21

Hannerz, U. (1992). Cultural Complexity: Studies in the Social Organization of Meaning. New York, NY: Colombia University Press.

Hoftsede, G. (1991). Cultures and Organizations: Software of the Minds. London: McGraw-Hill.

Horschild, A. R. (2018). Emotions in Organizations and in the Military. In J. L. Soeters (Ed.), Sociology and Military Studies: Classical and Current Foundations (pp. 157-168). New York, NY: Routledge.

Janowitz, M. (1977). Military Institutions and Coercion in the Developing Nations. Chicago, IL: University of Chicago Press.

Kirkman, B. L., \& Shapiro, D. L. (1997). The Impact of Cultural Values on Employee Resistance to Teams: Towards a Model of Globalized Self-Managing Work Team-Effectiveness. Academy of Management Review, 22, 730-757.

https://doi.org/10.5465/amr.1997.9708210724

Kummel, G. W. (2006). A Soldier is a Soldier, Is a Soldier!? The Military and It's Soldiers in Era of Globalization. In G. Caforio (Ed.), Handbook of the Sociology of Military (pp. 417-436). New York, NY: Springer. https://doi.org/10.1007/0-387-34576-0 24

Lammers, C. (2018). Strike and Mutinies, Occupational Styles and Cooperation. In J. Soeters (Ed.), Sociology and Military Studies: Classical and Current Foundations (pp. 143-156). New York, NY: Routledge.

Lamontagne, A. G., Keegel, T., Louie, M., Osty, A., \& Landsbergis, A. P. (2007). A System of Review of the Job-Stress Intervention Evaluation Literature, 1990-2005. International Journal of Occupational and Environmental Health, 13, 268-280. https://doi.org/10.1179/oeh.2007.13.3.268

Lang, K. (1972). Military Institutions and the Sociology of War. Beverly Hills, CA: Sage.

Laurence, J. H., Milavec, B. L., Rohall, D. E., Morten, G., Ender, G.M., \& Matthews, M. D. (2017). Predictors of Support for Women in Military Roles: Military Status, Gender, and Political Ideology. Military Psychology, 28, 488-497.

https://doi.org/10.1037/mil0000142

Martin, J. (1992). Cultures in Organizations: Three Perspectives. Oxford: Oxford University Press.

Martin, L. M. (2006). Soldiers and Governments in Post Praetorian Period. In G. Caforio (Ed.), Handbook of the Sociology of Military (pp. 189-202). New York, NY: Springer.

Moskos, C. C. (1977). From Institution to Occupation: Trends in Military Organization. Armed Forces and Society, 4, 41-50. https://doi.org/10.1177/0095327X7700400103

Moskos, C., \& Wood, F. R. (1988). The Military: More than a Job? Washington DC: Pergamon-Brassey's.

Official Site of Turkish Gendarmerie General Command (2021). http://www.jandarma.gov.tr

Scott, S., \& Bruce, R. (1994). Determinants of Innovative Behaviour: A Path Model of Individual Innovation in the Work Place. Academy of Management, 37, 580-607. 
Segal, M. W. (1986). The Military and the Family Greedy Institution. Armed Forces and Society, 13, 9-38. https://doi.org/10.1177/0095327X8601300101

Soeters, J. L. (2018). Sociology and Military Studies: Classical and Current Foundations. New York, NY: Routledge. https://doi.org/10.4324/9781315182131

Soeters, J. L., \& Winslow, D. J. (2006). Military Culture. In G. Caforio (Ed.), Handbook of the Sociology of Military (pp. 237-254). New York, NY: Springer. https://doi.org/10.1007/0-387-34576-0 14

Suliman, A. M. T. (2001). Are We Ready to Innovate? Work Climate-Readiness to Innovate Relationship: The Case of Jordan. Creativity and Innovation Management, 10, 49-59. https://doi.org/10.1111/1467-8691.00190

Turner, V. W. (1969). Liminality and Communitas. The Ritual Process: Structure and Anti-Structure. Chicago, IL: Aldine.

Von Clausewitz, C. (1989). On War. Princeton, NJ: Princeton University.

Weibull, L. (2012). Emotion Matters: Emotion Management in Swedish Peace Support Operations. Karlstad: Karlstad University Studies.

Weick, K. E. (1993). The Collapse of Sense Making in Organization. Administrative Science Quarterly, 38, 628-652. https://doi.org/10.2307/2393339

White, C. H., Godart, F. C., \& Thiemann, M. (2013). Turning Points and Space of Possibles: A Relational Perspective on the Different Forms of Uncertainty. In F. Depelteau, \& C. Powell (Eds.), Applying Relational Sociology: Relational, Networks and Society (pp. 137-154). New York, NY: Palgrave Macmillan. https://doi.org/10.1057/9781137407009 6

Winslow, D. (2000). Strange Bedfellows in Humanitarian Crisis: NGO and the Military. Military Spectator, 10, 525-534. 